\title{
A ciência na TV aberta: uma exploração da programação de emissoras de Belém-PA
}

\section{Maria Ataide Malcher, Weverton Raiol, Suzana Cunha Lopes, Jane Aparecida Marques, Luisa Massarani e Vanessa Brasil de Carvalho}

\begin{abstract}
Resumo
0 artigo analisa a presença da ciência na grade de programação televisiva aberta em duas emissoras de Belém-PA, a TV Liberal e a Record Belém, respectivamente retransmissoras da Rede Globo e Rede Record. A partir da técnica de semana construída e de análise de conteúdo, mapeou-se a presença da ciência na programação local, considerando as produções locais e nacionais. Destaca-se que a ciência está presente diariamente em todas as faixas horárias da TV aberta; a publicidade é um dos principais agentes configuradores deste cenário; e a programação local é centrada no que é produzido nacionalmente, ocasionando uma produção local esmaecida e com pouca presença da ciência.
\end{abstract}

Palavras-Chave

TV aberta. Ciência. Programação local.

Maria Ataide Malcher I ataidemalcher@uol.com.br Doutora em Ciências da Comunicação pela Universidade de São Paulo - USP, Brasil. Professora do Programa de Pós-Graduação em Comunicação, Cultura e Amazônia da Universidade Federal do Pará - UFPA, Brasil - e do Programa de Pós-Graduação em Divulgação da Ciência, Tecnologia e Saúde da Casa de 0swaldo Cruz - FIOCRUZ, Brasil.

Weverton Raiol I weverton.raio|@gmail.com Mestre em Ciências da Comunicação pelo Programa de PósGraduação Comunicação, Cultura e Amazônia da Universidade Federal do Pará - UFPA, Brasil. Pesquisador do Laboratório de Pesquisa e Experimentação em Multimídia da AEDi-UFPA.

Suzana Cunha Lopes I suzanaclopes@yahoo.com.br Doutoranda pelo Programa de Pós-Graduação em Comunicação Social da Universidade Federal de Minas Gerais - UFMG, Brasil. Pesquisadora do Laboratório de Pesquisa e Experimentação em Multimídia da AEDi-UFPA.

\section{Introdução}

A ciência é um dos saberes que constitui nosso cotidiano, portanto é assunto que permeia decisões políticas, econômicas, sociais e, por conseguinte, circula na mídia. Foi com 0 intuito de perceber a circulação midiática da ciência, sobretudo na TV, que foi desenvolvido um estudo para identificar a presença da ciência em diferentes gêneros e formatos da programação televisiva aberta no Brasil ${ }^{1}$.

Jane Aparecida Marques I janemarq.each@gmail.com Doutora em Ciências da Comunicação pela Universidade de São Paulo - USP, Brasil. Professora do Programa de Pós-Graduação Interunidades em Estética e História da Arte da USP e do Programa de Pós-Graduação em Comunicação Cultura e Amazônia da Universidade Federal do Pará - UFPA, Brasil.

Luisa Massarani | luisa.massarani5@gmail.com Doutora em Educação, Difusão e Gestão em Biociências pela Universidade Federal do Rio de Janeiro - UFRJ, Brasil. Professora do Programa de Pós-Graduação em Divulgação da Ciência, Tecnologia e Saúde da Casa de 0swaldo Cruz - FIOCRUZ, Brasil. Bolsista Produtividade do CNPq (Nível 1C).

\section{Vanessa Brasil de Carvalho}

vanessabrasilcarvalho@gmail.com

Doutoranda pelo Programa de Educação, Difusão e Gestão em Biociências da Universidade Federal do Rio de Janeiro - UFRJ, Brasil. Bolsista CAPES. 
A proposta de analisar a grade de programação como um todo promove a possibilidade de compreender melhor as estratégias que envolvem os usos da ciência na TV. Primeiramente por conta das linguagens de cada gênero e formato e os processos comunicacionais que elas podem acionar, mas também porque os perfis das emissoras, as faixas horárias e outras especificidades da TV aberta podem conter pistas importantes para entender as estratégias de representação da ciência, e da própria TV aberta, como meio de comunicação massivo, e sua relação com os seus consumidores.

Cabe destacar que foram utilizadas experiências anteriores de análise do jornalismo, como os estudos da Rede de Monitoramento e Capacitação em Jornalismo Científico (Redejc) (RAMALHO et $a l ., 2012)$ e pesquisas de telejornais (ANDRADE, 2004; MASSARANI et al., 2005; RAMALHO,

2013) e de reportagens em revistas eletrônicas (RONDELLI, 2004; MASSARANI et al., 2013).

Neste artigo, um desdobramento do estudo sobre a ciência na TV aberta brasileira, a proposta é dar luz às observações feitas sobre a programação televisiva local ${ }^{2}$, especificamente das emissoras TV Liberal e TV Record Belém, percebendo a pouca representatividade da produção local na grade de programação das emissoras e, consequentemente, a pouca ou ausente presença da ciência nos programas locais.

\section{Os percursos e escolhas da pesquisa}

A pesquisa partiu da possibilidade de contribuir com o desenvolvimento e refinamento de procedimentos de análise da ciência nos meios de comunicação, especialmente na TV, oferecendo subsídios para outras pesquisas no âmbito da divulgação científica e da comunicação da ciência.

Baseada em esforços já realizados, como 0 protocolo de análise desenvolvido pela Redejc para análise da ciência na mídia informativa (RAMALHO et al., 2012), analisar a ciência na programação de TV aberta brasileira estendeu o olhar para os diversos gêneros e formatos que compõem a grade de programação televisiva (MACHADO, 2003; SOUZA, 2004; PALLOTTINI, 2012), como o entretenimento, a publicidade, a

0 estudo em questão é a pesquisa "Representações da Mulher Cientista na TV Brasileira e no Imaginário de Adolescentes", financiada pelo Conselho Nacional de Desenvolvimento Científico e Tecnológico por meio da Chamada MCTI/CNPq/SPM-PR/MDA No 32/2012.

Considerando a proposta deste artigo, é importante ressaltar o entendimento sobre os termos programação nacional, programação local, produção nacional e produção local. Nas discussões apresentadas, ao utilizar o termo programação nacional nos referimos ao que é veiculado pelas emissoras sedes (Rede Globo e Rede Record), localizadas no Rio de Janeiro-RJ, enquanto a programação local diz respeito ao que foi veiculado pela emissoras filial/afiliada (TV Liberal e Record Belém), localizadas em Belém-PA. Do mesmo modo, indica-se como produção nacional o que é produzido diretamente pelas sedes e seus anunciantes, e como produção local o que é produzido diretamente pela filial/afiliada e seus anunciantes. Portanto, a análise da programação local considera tanto produções locais, quanto as nacionais, desde que veiculadas nas emissoras de Belém. 
educativa e outros ${ }^{3}$. A partir dessa ampliação, a pesquisa desenvolveu um novo protocolo de análise de conteúdo que possibilitou identificar e analisar a presença da ciência nas categorias televisivas para além da informativa.

A opção pela programação analisada teve como base os índices e os perfis de audiência das emissoras de TV aberta no Brasil, na qual foram selecionadas as emissoras líderes em diferentes públicos: a Rede Globo e a Rede Record (MÍDIA DADOS BRASIL, 2016). Além disso, considerando que a TV aberta brasileira possui um sistema de transmissão, no qual, segundo Miranda (2013), existe uma programação produzida e transmitida pela sede das emissoras, normalmente localizadas na região Sudeste, para as suas filiais e afiliadas ${ }^{4}$ distribuídas em todo 0 território nacional, há diferenças na produção e veiculação de conteúdos nas diversas cidades do país. Portanto, a pesquisa se preocupou em monitorar e analisar programações das emissoras no Rio de Janeiro, sua sede de distribuição, e em Belém, visando à observação das relações entre as grades de programação nacionais e locais.

Após a seleção das emissoras e seus locais de transmissão, a pesquisa se voltou para 0 modo de selecionar e monitorar a programação a ser analisada. Tendo também como referências os estudos já realizados pela Redejc (RAMALHO et al., 2012) e por Whitelegg e colaboradores (2008) sobre as representações de gênero de cientistas, engenheiros e matemáticos na programação infantil das TVs do Reino Unido, a construção do corpus iniciou pela técnica de semana construída. A técnica consiste na coleta de dados em momentos distintos para a formação de períodos representativos para a análise de produtos dos meios de comunicação que possuem periodicidade.

Optou-se pela semana construída considerando a lógica vertical e horizontal de distribuição semanal de conteúdo da programação da TV aberta no Brasil (MALCHER, 2009)5 . Nesta lógica,

Souza (2004) apresenta os gêneros e formatos das seguintes categorias televisivas da TV aberta brasileira: informativa, entretenimento, publicidade e educativa; mas também aponta que existem categorias não aprofundadas em sua pesquisa. Neste estudo foram identificadas presença e menções à ciência em programas religiosos, categorizados no protocolo que desenvolvemos como outros, por considerar que outras categorias não aprofundadas por Souza (2004) pudessem ser identificadas no decorrer da pesquisa.

As filiais/afiliadas, também denominadas como repetidoras locais, estão distribuídas por todo o país e retransmitem a programação da sede quase integralmente, mas possuem horários específicos para as inserções de programação local (MIRANDA, 2013). Cabe ressaltar que a forma de filiação das repetidoras locais reflete não somente em espaços na grade de programação, mas também nas formas de produção do conteúdo. Miranda (2013) aponta, por exemplo, que as filiais tendem a ser extensões de suas sedes, pois estão diretamente subordinadas a elas, enquanto as afiliadas também possuem diretrizes de produção, mas tendem a possuir mais autonomia com seus espaços e produtos.

A TV Excelsior, na década de 1960, trouxe várias inovações administrativas e gerenciais para o fazer televisivo brasileiro, a partir do modelo organizacional norte-americano. Entre outras coisas, a emissora foi a responsável pelo estabelecimento da lógica da grade de programação: "[...] a grade de programação horizontal institucionaliza horários para veiculação dos programas de segunda a domingo e estabelece em simultaneidade a verticalização da programação que pressupõe a continuidade de assistência às próximas atrações ao longo do dia [...]" (MALCHER, 2009, p. 113). A emissora inaugurou essa dinâmica, mas foi a Rede Globo, na década seguinte, que a aprimorou e consolidou o modelo existente até hoje na TV aberta brasileira. 
foram construídas duas semanas de programação de cada emissora selecionada, com dias de programação coletados entre junho e novembro de 2013 por meio de sorteio aleatório, que se torna mais representativo do que duas semanas ininterruptas, por permitir um olhar diacrônico em um período mais longo. As semanas foram construídas, portanto, com duas vezes cada dia da semana, distribuídas por um semestre (Quadro 1).

A partir dessas definições, foram gravadas e armazenadas 1.320 horas da programação, sendo
648 horas em Belém ${ }^{6}$ e as demais no Rio de Janeiro para monitoramento. A programação foi assistida para selecionar as peças a serem analisadas, ou seja, os programas ou partes deles $^{7}$ que faziam direta ou indiretamente referência à ciência. 0s critérios estabelecidos para seleção foram: 1) Presença e/ou menção direta à ciência, cientistas, pesquisa, pesquisadores ou acadêmicos; 2) Presença e/ou menção de especialistas $;$; 3) Menção de dados e termos científicos; 4) Presença de ilustração, animação e efeitos

Quadro 1: Semanas construídas: dias sorteados para assistência e análise em 2013.

\begin{tabular}{|c|c|c|}
\hline Dias da semana & $1^{\text {a }}$ semana & $2^{\text {a }}$ semana \\
\hline Domingos & 22 de setembro & 29 de setembro \\
\hline Segundas-feiras & 19 de agosto & 16 de setembro \\
\hline Terças-feiras & 18 de junho & 29 de outubro \\
\hline Quartas-feiras & 18 de setembro & 13 de novembro \\
\hline Quintas-feiras & 12 de setembro & 24 de outubro \\
\hline Sextas-feiras & 04 de outubro & 29 de novembro \\
\hline Sábados & 31 de agosto & 14 de setembro \\
\hline
\end{tabular}

Fonte: Elaborado pelos autores.

A proposta inicial de coleta resultaria em 1.344 horas gravadas de programação, equivalentes a 14 dias transmitidos por cada emissora nas duas cidades. Entretanto, especificamente na coleta da programação de Belém houve dois problemas técnicos: a) a programação da TV Liberal no dia 18 de junho de 2013 (terça-feira) foi gravada sem áudio, mas sua análise foi possível a partir de uma primeira assistência e posterior busca dos vídeos em servidores de vídeo na internet e acervo online da TV Liberal e da Rede Globo; b) a programação da Record Belém do dia 31 de agosto de 2013 (sábado) teve seus arquivos corrompidos, gerando perda das informações (equivalentes a 24 horas de programação).

No protocolo de pesquisa foram consideradas como peças tanto programas completos quanto parte deles: reportagens; quadros de programas; cenas de telenovelas, filmes, séries, desenhos animados; anúncios publicitários; entre outros.

Cabe destacar que o critério menção e/ou presença de especialistas foi mantido nas análises realizadas sobre a programação televisiva veiculada em Belém. Nesse sentido, é importante enfatizar que especialistas são todos os profissionais de Ensino Superior que falam a partir da sua área de formação sobre o que é tratado nas peças e que não são identificados explicitamente como cientistas. Este critério, portanto, possibilita selecionar para análises peças que recorrem a atores e vozes que não são explicitamente cientistas, entretanto, apresentam e recorrem a conhecimentos que podem ser relacionados à ciência principalmente em anúncios publicitários, um dos desdobramentos futuros da pesquisa. 
especiais como representação da ciência; 5)

Divulgação da ciência ${ }^{9}$.

Ao final, foram identificadas 1.523 peças $^{10} \mathrm{em}$

Belém, que atendiam, no mínimo, a um dos

cinco critérios que identificam a presença ou

menção de representações da ciência na grade de

programação (Gráfico 1).

Uma observação importante para interpretação dos dados é atentar que uma mesma peça pode atender a mais de um critério simultaneamente, já que eles não são excludentes. Sendo a menção de dados e termos científicos $(63,2 \%)$ o critério mais presente, seguido da presença e ou menção de especialistas $(55,2 \%)$ e a presença de ilustração, animação e efeitos especiais como representação da ciência (40,8\%). Os critérios presença ou menção direta à ciência, cientistas, pesquisa, pesquisadores ou acadêmicos (23,3\%) e divulgação da ciência (2\%) são, respectivamente, os critérios menos presentes no corpus analisado.

É necessário o destaque à pouca expressividade de divulgação da ciência, que de certo modo indica que são poucos os conteúdos produzidos com este fim específico e direto na TV aberta brasileira, um primeiro indício que a ciência, como área, pouco produz materiais televisivos

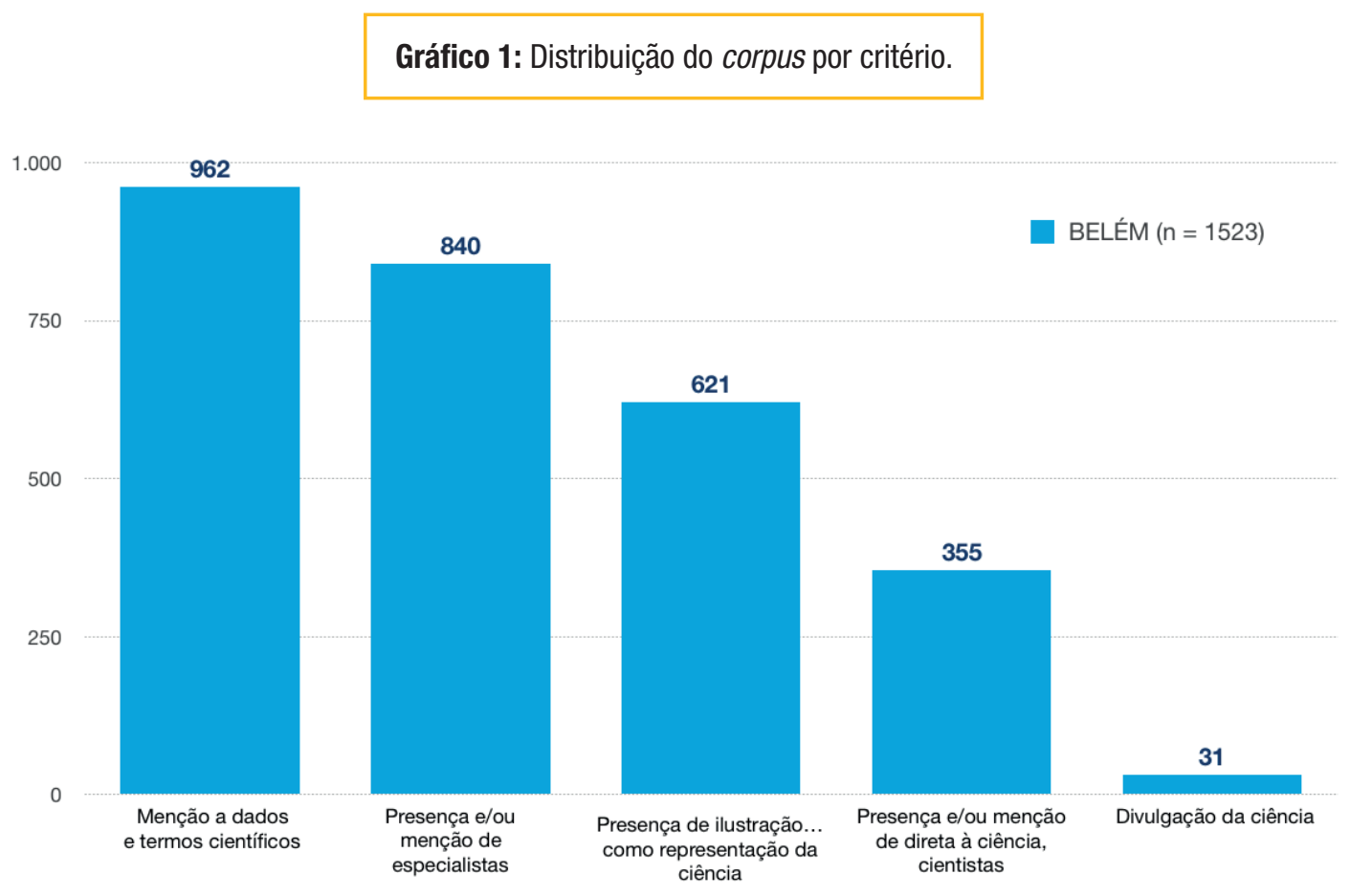

Fonte: Elaborado pelos autores.

A explicitação desses critérios pode ser vista em Carvalho e colaboradores (2015).

10 As 1.523 peças analisadas representam 11,5\% (72 horas, 44 minutos e 57 segundos) das 648 horas de programação monitoradas em Belém. 
voltados para a sociedade. No entanto, isso não quer dizer que não haja outros diálogos com a ciência no cotidiano, pois ela está presente em programações televisivas com outros fins, como filmes e desenhos animados, além de estar em outros meios, como livros e gibis. Sendo assim, exatamente por fazer parte do cotidiano, ela se torna presente nas várias formas que os sujeitos significam as questões do mundo.

Como a pesquisa foi realizada em duas cidades, conseguimos perceber que a programação veiculada em Belém possui um perfil muito próximo do que foi veiculado no Rio de Janeiro. A distinção está nos espaços dedicados à produção local. Desta forma, aqui explicitam-se os caminhos e resultados alcançados a partir da análise das grades de programação televisiva veiculadas em Belém pela TV Liberal e Record Belém. Essa opção permite uma análise mais verticalizada sem perder a correspondência que há com os dados nacionais, focando, sempre que possível, nas especificidades desse cenário.

\section{Ampliando o olhar e 0 escopo das análises}

Antes de apresentar os resultados desse mapeamento das emissoras de TV regionais, a partir da experiência de pesquisa em Belém, considera-se importante apontar as reconfigurações realizadas no Protocolo da Redejc para a montagem do novo protocolo utilizado na pesquisa, que teve como base a revisão bibliográfica sobre gêneros e formatos televisivos (MACHADO, 2003; SOUZA, 2004; PALLOTTINI, 2012). 0 processo de reconfiguração do protocolo de análise, como mencionado, ampliou as possibilidades de estudos das categorias televisivas, incluindo, além da categoria informativa, 0 entretenimento, a publicidade, a programação educativa e outras que compõem a grade de TV aberta no Brasil.

A revisão bibliográfica permitiu, para além da classificação de categorias, gêneros e formatos televisivos, repensar as dimensões e categorias de análise de conteúdo do Protocolo da Redejc, para viabilizar seu uso em produtos diferentes dos jornalísticos e informativos. Nesse processo houve adequações e inclusões de categorias, fato que ampliou as possibilidades de análise.

Um exemplo de inclusão de dados no protocolo está na dimensão de análise denominada características gerais, na qual foram inseridas categorias mais específicas sobre a veiculação das peças analisadas, como os horários e locais de veiculação, permitindo mapear, na lógica horizontal e vertical da programação de TV aberta brasileira, a presença da ciência.

0 novo protocolo também incluiu a classificação de gêneros e formatos televisivos como uma dimensão de análise, uma mudança estrutural significativa para melhores descrições das peças analisadas. Outro ponto essencial foi a atribuição de novos sentidos ao modo de analisar algumas 
categorias, como é o caso das fontes, promessas e contextualização da ciência, dimensões bastante pertinentes para programações informativas, mas que precisaram ser ressignificadas para outros gêneros, como o publicitário, por exemplo.

Para maior clareza da contribuição de cada uma das dimensões de análise nos resultados alcançados, apresenta-se breve configuração do protocolo final da pesquisa. Na dimensão características gerais foram coletados os dados de identificação da peça na amostra, contendo basicamente os seus dados de veiculação (datas, horários, duração, localização na programação, entre outros), importantes para visualizá-las na grade de programação. Já a dimensão tema visava a identificar os assuntos principais das peças e a qual área de conhecimento ${ }^{11} 0$ conteúdo estava relacionado.

\section{Características de formato e conteúdo foi a} dimensão inserida no protocolo a partir das categorias, gêneros e formatos da TV aberta brasileira apresentados por Souza (2004), Machado (2003) e Pallottini (2012). Essa dimensão tinha por objetivo identificar as características das peças selecionadas, apontando se são unitárias, seriadas, ao vivo, entre outras.

\section{A presença de cientistas e presença de} especialistas são duas dimensões que possuem as mesmas categorias de análise, para identificar e caracterizar, respectivamente, os cientistas e especialistas presentes nas peças selecionadas. Além de quantificar a frequência e a duração da presença deles nas peças, por meio da codificação, essas duas dimensões possibilitam a caracterização dos atores por gênero, local de trabalho, acessórios utilizados, nacionalidade e cor da pele.

A dimensão narrativa foi direcionada para identificar o(s) elemento(s) central(is) da narrativa das peças a partir do conceito de enquadramento, visando a identificar e a analisar como se constrói sentido em torno da ciência. 0 tratamento é a sétima e mais abrangente dimensão de análise do protocolo, pois está direcionada aos recursos imagéticos, sonoros e textuais, incluindo os argumentos utilizados para construir o que é focalizado pela peça.

A dimensão atores, que finaliza o protocolo, está dividida em dois direcionamentos: fontes e vozes. Apesar de serem caracterizadas a partir de categorias de análise semelhantes, esses direcionamentos possuem diferenças: as fontes são todos os materiais consultados para elaborar a informação apresentada; as vozes são, efetivamente, todas as pessoas com oportunidade de fala na peça, portanto, também são fontes. Esta dimensão tem como proposta identificar as bases de legitimação científica que estão presentes na programação televisiva. 
Com base nesse protocolo, foram feitas as

análises das programações monitoradas em

Belém, resultando em um banco de dados com

as peças codificadas. A partir de processamentos

estatísticos e cruzamentos entre critérios, as

características de gênero e formato, os dados de

veiculação, os enquadramentos, o tratamento, entre

outras variáveis, esse banco de dados gerou dados

quantitativos sobre 0 corpus. Os processamentos

de dados foram realizados no IBM SPSS Statistics,

software para análises estatísticas em Ciências

Sociais. Foram obtidas a frequência da presença

da ciência na grade de programação televisiva,

percebendo os gêneros e formatos que mais recorrem

aos elementos da ciência, e quais estratégias de

enquadramento e tratamento são mais comuns sobre

a ciência, como apresentado a seguir.

\section{Observando alguns resultados}

A análise da programação televisiva permitiu compreender aspectos da presença da ciência na grade de programação e nos produtos televisivos. A programação observada em Belém gerou um corpus composto por 1.523 peças, sendo 51,7\% (787) veiculadas na Record Belém e 48,3\% (736) na TV

Liberal. Esses resultados podem, ainda, ser subdivididos pela abrangência de produção e veiculação da programação, sendo nacional ou local. Desse modo, destacam-se que na Record Belém há 3,4\% (51) e na TV Liberal $3,2 \%$ (49) das peças veiculadas de produção local, somando 6,6\% (100) das peças em todo corpus (Gráfico 2).

Gráfico 2: Distribuição do corpus por emissora e tipo de produção.

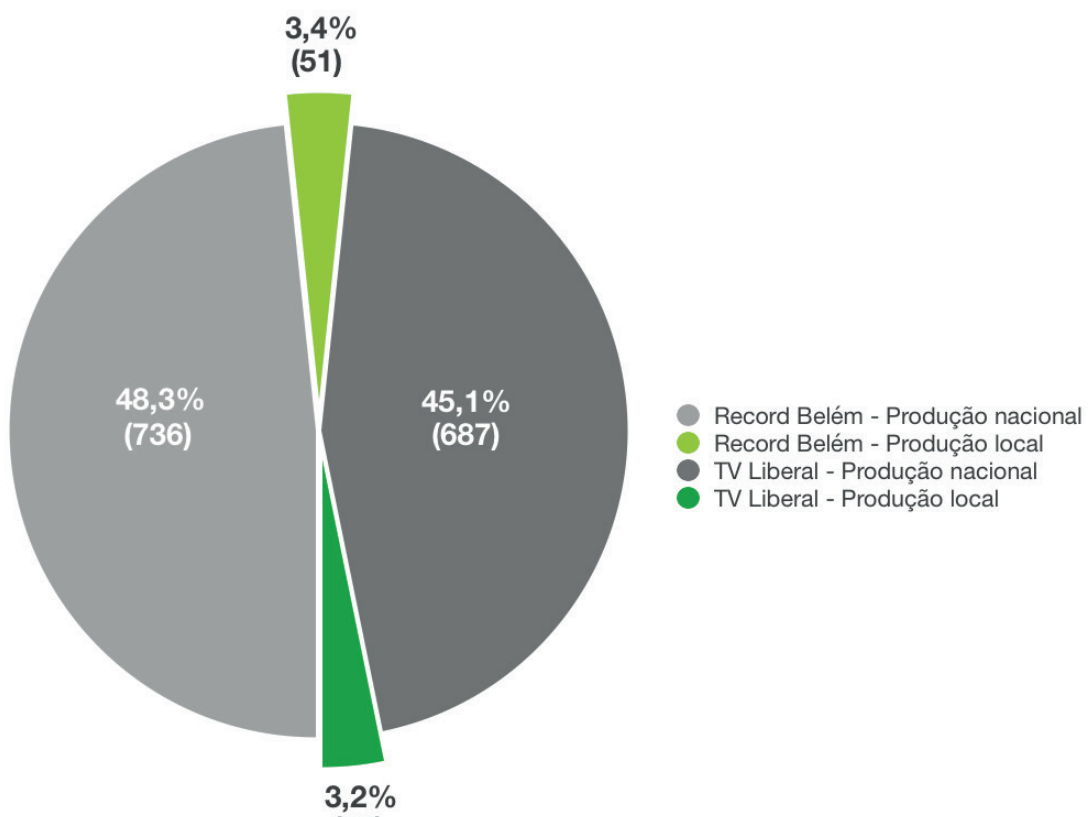

(49)

Fonte: Elaborado pelos autores. 
A Record Belém possui o maior número de veiculações de peças relacionadas à ciência, no entanto, entre as emissoras, é perceptível a proximidade dos números, principalmente da produção local. Esta configuração está diretamente relacionada às características de transmissão da TV aberta brasileira, na qual, como já citado, há um espaço determinado para veiculação do que é produzido localmente, com variações conforme 0 tipo de afiliação das emissoras locais.

Essa constatação demonstra a pequena participação da produção local na lógica da TV aberta brasileira. Esses são reflexos da implantação de um sistema televisivo centralizador, que se de um lado beneficiou a constituição da TV no Brasil, por outro esmaeceu quase completamente a produção televisiva local (MALCHER, 2009). Desta forma, os dados obtidos levam a discutir a lógica que constitui a TV aberta e as especificidades da temática científica inseridas nesse contexto.

Sabe-se que a configuração da programação nacional é refletida na programação local. Contudo, a distribuição de peças por critério e categoria televisiva, por exemplo, permite identificar algumas especificidades do local. Ao isolar a produção local que atende aos critérios da pesquisa, percebe-se que algumas categorias televisivas se mostram mais recorrentes ou completamente ausentes, comparando-as ao cenário da produção nacional.
Considerando a composição do corpus a partir da produção nacional veiculada em Belém, como já foi citado, há destaque para as peças que fazem menção a dados e termos científicos, presença e/ou menção de especialistas e a presença de ilustração, animação e efeitos especiais como representação da ciência. Essa configuração é alterada quando se isola a produção local, na qual a presença e/ou menção de especialistas (81\% local) assume a posição de mais recorrente, a menção a dados e termos científicos (58\% local) cai para a segunda posição e a presença de ilustração, animação e efeitos especiais como representação da ciência (13\% local) se torna bem menos expressiva entre os critérios (Gráfico 3). 
Gráfico 3: Distribuição do corpus por critério de seleção e tipo de produção.

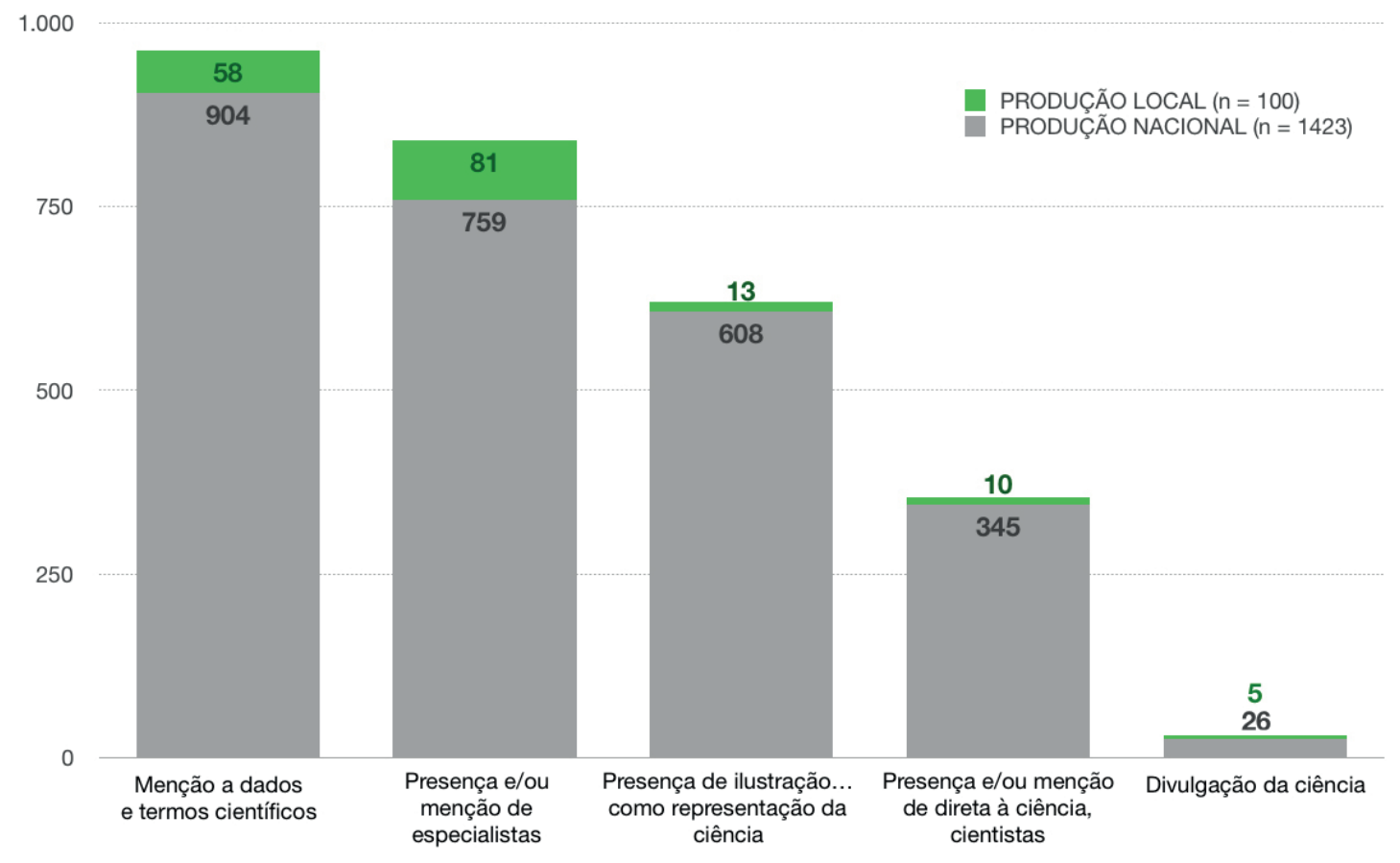

Fonte: Elaborado pelos autores.

A presença elou menção direta à ciência, cientistas, pesquisa, pesquisadores ou acadêmicos (10\% local) e a divulgação da ciência (5\% local) são critérios menos expressivos na composição do corpus como um todo, sendo na produção local uma recorrência ainda menor. De certo modo, essa é uma indicação de que a ciência e seus atores mais tradicionais (cientistas, pesquisadores etc.) são apresentados de forma menos explícita. Também é notável a ausência de produções voltadas especificamente para a divulgação científica na TV aberta, sobretudo na produção local, indicando que a presença da ciência que é recorrente na programação possui outros fins, como entreter ou persuadir.
Essa configuração da distribuição por critérios pode estar relacionada diretamente às categorias, aos gêneros e aos formatos da TV aberta (MACHADO, 2003; SOUZA, 2004; PALLOTTINI, 2012), pois a predominância da publicidade (Gráfico 4) no corpus configura alguns pontos importantes que suscitam sobre a recorrência dos critérios. 
Gráfico 4: Distribuição do corpus por categoria televisiva e tipo de produção.

800

PRODUÇÃO LOCAL $(n=100)$

PRODUÇÃO NACIONAL $(n=1423)$

600

0

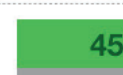

740
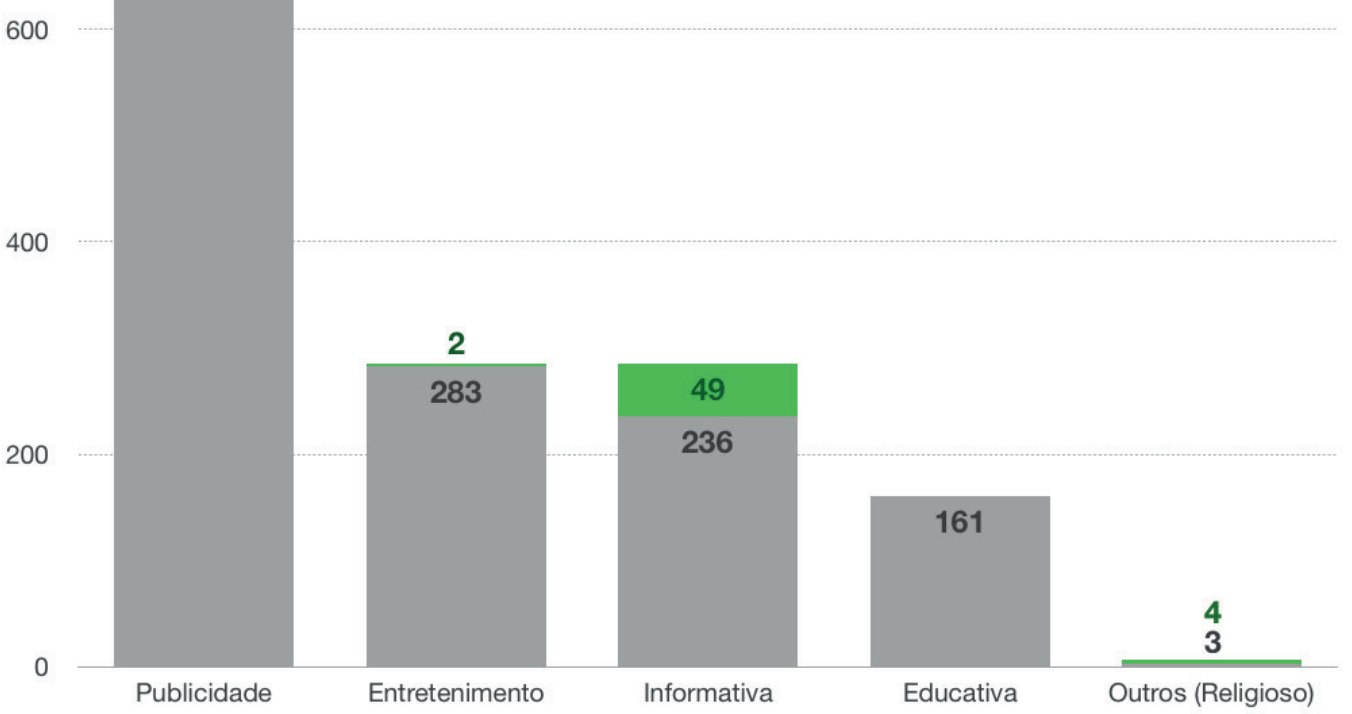

Fonte: Elaborado pelos autores.

A expressividade da publicidade no corpus, em aspecto quantitativo, configura um cenário relevante, porque os anúncios publicitários representam mais da metade das peças selecionadas e analisadas: são 51,5\% (795). Essa quantidade deve ser pensada a partir da característica publicitária de reinserções diárias e semanais na grade de programação televisiva, pois há repetições de anúncios nas duas emissoras monitoradas.

Constatações como essas indiciam a pensar a comunicação publicitária com temas científicos como importante objeto para análise, devido suas especificidades em relação às demais categorias televisivas. Pode-se retornar aos critérios, considerando a publicidade como a categoria mais presente, e perceber como a recorrência deles está relacionada às estratégias presentes nos anúncios publicitários. Logo, entende-se que 0 uso de dados, termos, ilustrações e especialistas, como representantes da ciência, são estratégias persuasivas presentes em muitos anúncios analisados, por se mostrarem argumentos potenciais para as narrativas publicitárias, dando à ciência 0 papel de legitimadora do que foi dito ou demonstrado.

É preciso considerar que o número elevado de peças da categoria publicitária está relacionado às características importantes de sua constituição na TV: os anúncios publicitários possuem tempo reduzido e justamente por isso são inseridos de formas diversas 
na grade televisiva, como estratégia de reforço do que se pretende publicizar, oportunizando que se encontrem repetições e variações de um mesmo anúncio ou campanha publicitária diversas vezes no corpus, em diferentes emissoras e em momentos distintos da programação.

As categorias entretenimento e informativa têm 18,7\% (285) das peças cada uma, enquanto a categoria educativa possui 10,6\% (161) e outras, que neste caso é religiosa, possui 0,5\% (7) das peças compondo o corpus. Observando especificamente a produção local, percebese que a categoria informativa se destaca em relação às demais, inclusive sobre a publicidade. Isso está relacionado ao fato de que o espaço definido para a veiculação da produção local é utilizado majoritariamente pelo jornalismo e pelos anunciantes locais e raramente pelas demais categorias televisivas, pois são poucos os casos de programas de entretenimento e inexistentes os conteúdos educativos locais no corpus. Essa é apenas mais uma constatação do esmaecimento da produção local, que geralmente se constitui por conteúdos de menor custo para as emissoras, como os telejornais.

\section{É interessante perceber também como as} categorias e os critérios de seleção do corpus se relacionam. No caso da publicidade, por exemplo, é possível perceber especificidades dos anúncios publicitários para utilização da ciência (Gráfico 5).

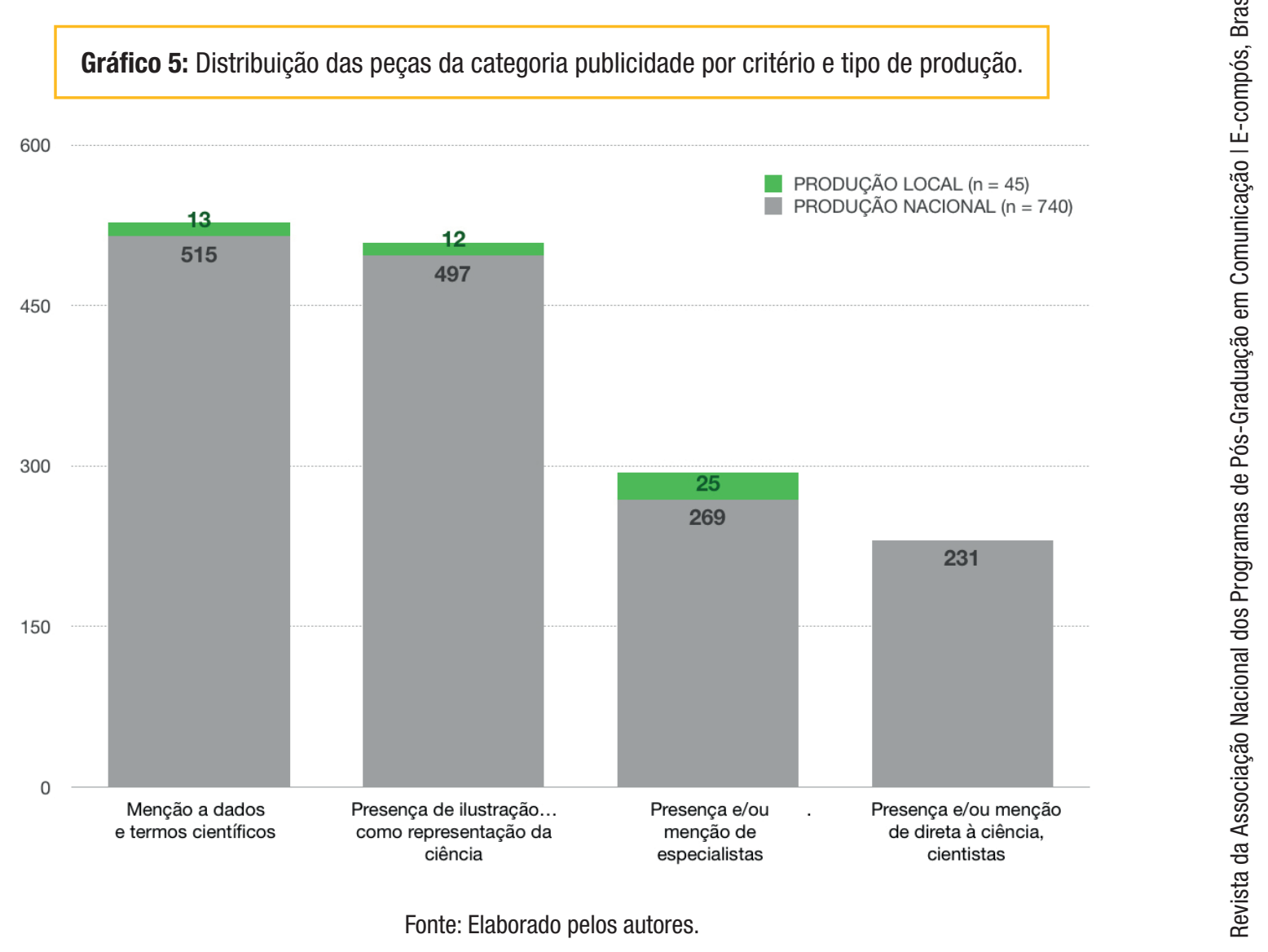


A menção a dados e termos científicos permanece como o critério mais recorrente na publicidade, contudo a presença de ilustração, animação $e$ efeitos especiais como representação da ciência se torna o segundo critério mais recorrente nessas peças. Isso parece indicar que o uso de dados e de demonstrações por meio de animações podem ser mais estratégicas à narrativa publicitária. A presença e/ou menção direta à ciência, cientistas, pesquisa, pesquisadores ou acadêmicos é menos presente nos anúncios publicitários e a divulgação científica inexistente. 0 cenário delineado pela categoria publicitária contribui significativamente para o cenário já apresentado da distribuição do corpus por critério.

Para além da identificação das recorrências da ciência em categorias televisivas, é importante entender como este conteúdo está distribuído na grade de programação. A Record Belém e TV Liberal apresentam perfis distintos na distribuição das categorias televisivas. Nas duas emissoras há predominância de peças da categoria televisiva publicidade, contudo, essa expressividade é maior na Record Belém, na qual aproximadamente $80 \%$ do corpus corresponde aos anúncios publicitários que lançam mão da ciência na construção das suas narrativas. Os demais $20 \%$ estão divididos entre as categorias informativa, de entretenimento e outras (religiosa). Na Record Belém, nenhum conteúdo educativo foi selecionado ou analisado, de acordo com os critérios da pesquisa. Já na TV Liberal, as peças se distribuem equilibradamente entre os conteúdos publicitários, de entretenimento, informativos e educativos. E, neste caso, já não há presença de outras categorias.

Outro ponto importante entre os resultados da pesquisa é a distribuição desses conteúdos ao longo da programação, como a forma que eles estão dispostos diariamente e por horário ${ }^{12}$. Os conteúdos relacionados à ciência estão distribuídos uniformemente durante toda a programação, com uma recorrência maior pela manhã, com 29,1\% (444) das peças. Em seguida, vêm os períodos da madrugada com $25 \%$ (381), da noite com $24 \%$ (365) e da tarde com 21,9\% (333).

A distribuição das peças por horário ressalta pontos importantes relacionados à programação monitorada. Durante a manhã, estão concentrados os programas de entretenimento do tipo variedade que, entre outros assuntos, abordam enfaticamente os temas da saúde, alimentação, entre outros. Programas como Bem Estar, na Rede Globo, e Hoje em Dia, na Rede Record, são janelas de aproximação aos conteúdos científicos. É possível verificar a presença da ciência em programações como desenhos animados ou programas voltados para a divulgação científica e assuntos acadêmicos, como o Globo Universidade e Globo Ecologia aos sábados. 
Em contraponto, os conteúdos como novelas, séries e telejornais estão concentrados em outros momentos do dia. É o caso do horário nobre noturno, que concentra uma programação considerada de prestígio para as emissoras, pelo qual são recebidos os maiores patrocínios e valores de anúncio, dando motivo para entender a noite como um período importante, mas nem sempre possível, dependendo da capacidade de investimento e planejamento de mídia dos anunciantes.

Como já indicada, a programação local se diferencia do cenário nacional porque seus espaços são utilizados principalmente para a produção de telejornais que normalmente são veiculados no início da manhã e no início e final da tarde. Fato que explica uma mudança nos horários de veiculação da ciência. Ao isolar a produção local, na qual a categoria televisiva informativa se destaca, a tarde, que é o período com menos recorrência, torna-se o período com mais veiculações de peças analisadas. Logo, a produção local com presença da ciência está, em sua maioria, no período da tarde.

A distribuição das peças ao longo da semana possui alguns destaques: uma redução expressiva dos conteúdos relacionados à ciência aos domingos, com 9,9\% (151) das peças analisadas; e quartas, com 19,8\% (302), e sextas-feiras, com 18,6\% (283), sobressaem-se como os dias com mais veiculações desses conteúdos. Nos demais dias da semana há certa uniformidade na distribuição desses conteúdos (Gráfico 6).

Gráfico 6: Distribuição do corpus por dias da semana e tipo de produção.

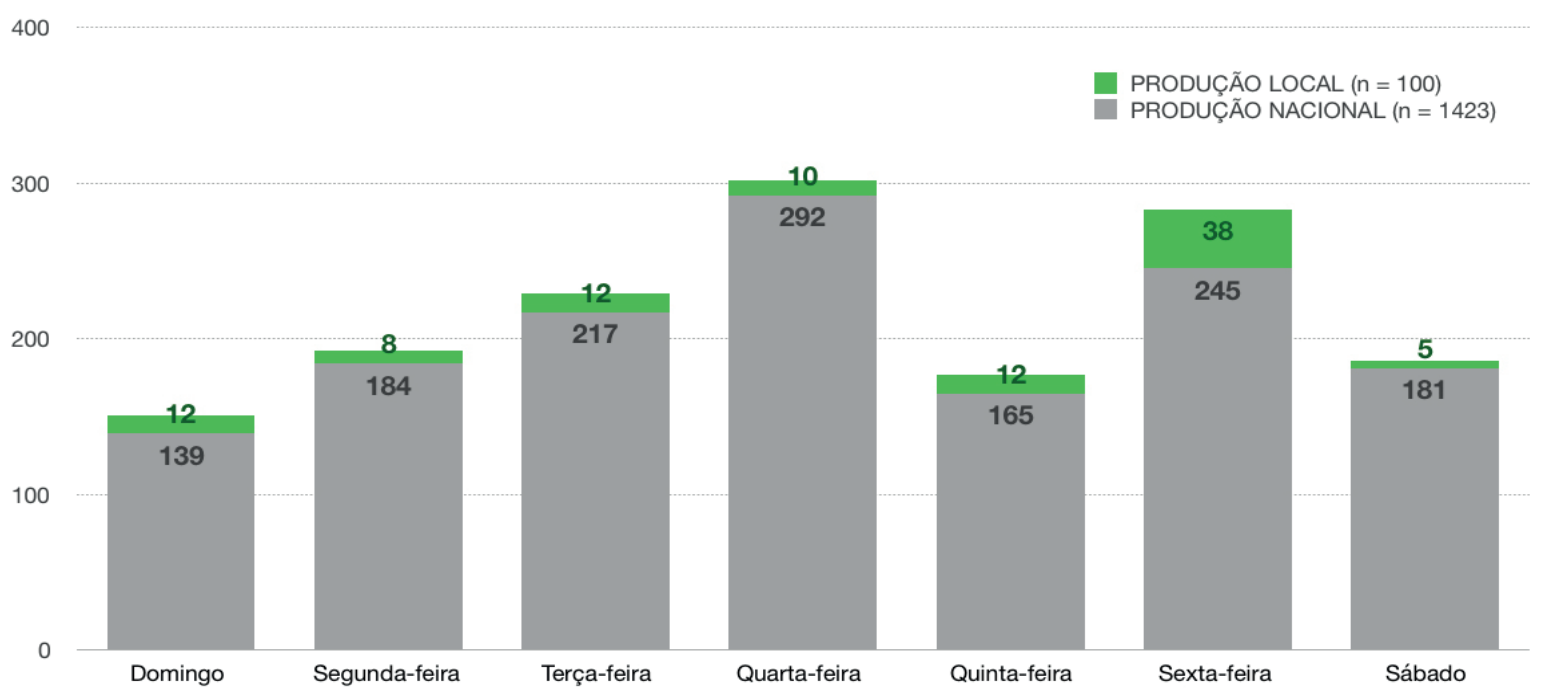

Fonte: Elaborado pelos autores. 
0 destaque da sexta-feira também é tido na produção local (38\% local) contabilizando as duas emissoras, já o sábado (5\% local) se torna o dia com menos conteúdos científicos. Podese perceber uma ciência presente em todos os dias e horários da programação televisiva, ou seja, uma frequência regular, característica da grade de programação da TV aberta brasileira, de continuidade ao longo do dia e da semana. Nessa perspectiva, enquadra-se também a publicidade e sua característica de inserções periódicas de anúncios, como uma estratégica tentativa de alcançar telespectadores a partir da programação veiculada.

Considerando, portanto, as emissoras, as categorias televisivas, as faixas de horário e outras questões que compõem a grade de programação televisiva aberta no Brasil, visualizam-se as programações que recorrem à ciência para construir suas narrativas, constatando que a grade é permeada diariamente em todas as faixas de horário pela temática científica por meio de diversas estratégias e linguagens.

Observando as peças por área de conhecimento, pode-se apontar que as Ciências Biológicas e da Saúde são predominantes na programação. Os dados e termos científicos, assim como os especialistas e cientistas identificados, pertencem, na maioria dos casos, a essas duas áreas. Mas novamente a produção local possui distinções em relação à nacional, pois, apesar de manter as Ciências Biológicas como mais recorrente, também dá vez às Ciências

Sociais Aplicadas.

A predominância de referências das Ciências Biológicas pode ser relacionada ao que percebemos sobre a construção históricosocial da ciência como uma das nossas formas de conhecer. Com o estudo de Wallerstein e colaboradores (1996), entendese que a ciência, desde a sua origem, está relacionada à racionalidade $\mathrm{e}$ a um sentido de verdade sobre 0 mundo, pautados a partir de mensurações e normatividades. Os autores indicam que as ciências (no plural, porque há diferentes formas de conhecer e ser considerado científico) têm suas trajetórias marcadas até hoje pelo que é exato, observável e quantificado. Fato que dá, por exemplo, à Biologia, à Matemática, entre outros, o título de conhecimentos consolidados. Logo, são áreas aptas a conhecer e serem reconhecidas como legitimadoras de informações sobre o mundo, o homem e outros seres vivos, em diversos âmbitos, inclusive na TV.

Sabe-se, no entanto, que não apenas as Ciências Biológicas gozam desse reconhecimento. Como já apresentado, outras disciplinas também possuem trajetórias muito ligadas ao que historicamente se constitui como ciência. É o que Santos (1999) denomina como paradigma dominante, ou seja, condições históricas e sociais pelas quais a ciência se constituiu e configura fortemente 0 
que se entende como tal, apesar de na atualidade serem feitas várias críticas a esse estatuto.

Como principal categoria televisiva identificada no corpus, a publicidade contribui para essa predominância da Saúde e da Biologia na programação analisada. Os anúncios publicitários que compõem o corpus divulgam produtos de diversas categorias de mercado, contudo, os medicamentos, os produtos de saúde corporal e bucal, os produtos de higiene e os alimentos são os mais frequentes. A abordagem encontrada nesses anúncios, principalmente naqueles relacionados à saúde e à estética, focaliza demonstrações dos efeitos dos produtos. Em aspectos quantitativos, 0 enfoque mais recorrente é a ciência apresentada a partir de questões estéticas, com 24,6\% (375) das peças analisadas, mais um ponto para refletir sem desconsiderar a presença expressiva da publicidade de produtos de beleza.

Outro recurso também muito presente, verificado em 16,7\% (255) das peças analisadas, é a personalização desses conteúdos, uma estratégia de uso de personagens para "dar vida" aos conteúdos científicos apresentados. A recorrência deste recurso remete ao uso que a publicidade, com anúncios testemunhais, e os programas informativos e de entretenimento, com entrevistas, fazem da ciência como legitimadora de dados e processos.

Percebe-se, por fim, que os tratamentos dados à ciência na TV aberta centram-se em torno de um caráter benéfico para a sociedade.
Das peças analisadas, $67,8 \%$ (1.032) delas apresentam benefícios, 54,7\% (833) trazem consigo recomendações e 52,4\% (798) mencionam promessas da ciência. Em número menor estão os casos nos quais a ciência se apresenta de maneira oposta: 20,7\% (306) das peças apresentam danos e 17,3\% (263) apontam riscos científicos. Para essas formas de apresentar a ciência, 43,1\% (657) das peças recorrem a contextualizações e 28\% (426) fazem o esclarecimento de termos científicos.

\section{Considerações finais}

Ao longo das análises percebe-se a pouca representatividade da produção local na grade de programação das emissoras paraenses TV Liberal e Record Belém. 0 peso das cabeças de rede sobre a programação revela o modelo brasileiro de produção e veiculação televisivas. Mas para além das diferenças quantitativas no que se refere ao local/nacional, também foi possível identificar distinções na forma como a ciência é abordada na programação local, permitindo, ainda que timidamente, as especificidades das produções dessas emissoras filiada e afiliada em Belém.

Outro resultado importante que emergiu dos dados analisados foi a quantidade expressiva das peças de publicidade. Entretanto, não é apenas uma questão numérica que foi suscitada, mas a importância de observar essa categoria televisiva com mais apuro, devido à sua natureza persuasiva e por ser financeiramente 0 que sustenta as emissoras de TV. 
É por representar mais da metade do corpus analisado que as características da abordagem da ciência na publicidade marcaram fortemente o mapeamento do corpus como um todo. Primeiramente é possível relacionar isso, por exemplo, à uniformidade das distribuições diárias e semanais de peças, à ênfase aos aspectos positivos da ciência, à redução de questões negativas, à recorrência de áreas do conhecimento relacionadas à natureza dos produtos mais anunciados, entre outros aspectos presentes na publicidade e que dão o tom de boa parte da análise do corpus.

De outro modo, pode-se analisar o uso da ciência adotado pela publicidade como um indicador de retornos das ações científicas ao senso comum, constituindo o que Santos (1999) estabelece como a necessidade da nova racionalidade da ciência no denominado paradigma emergente, conjuntura contemporânea. Para 0 autor: "0 conhecimento científico pós-moderno só se realiza enquanto tal na medida em que se converte em senso comum" (SANTOS, 1999, p. 57).

Nesse sentido, "sensocomunizar" o que é científico faz parte de um processo essencial para a ciência nos dias de hoje. Sobre o senso comum, Santos (1999) descreve características que 0 tornam diferente da ciência, mas não menos importante. 0 senso comum é prático e resulta de experiências de vida, é produzido de forma não orientada, ou seja, dá-se no cotidiano, tornando-se um conhecimento retórico e metafórico que não necessariamente ensina, mas persuade (SANTOS, 1999). Tem-se aí um aspecto importante para ser relacionado à publicidade, vendo-a como um possível movimento de "sensocomunização" da ciência a partir das suas narrativas, afinal, seu objetivo principal é comunicar, especialmente por meio de estratégias persuasivas (GOMES, 2008).

Neste artigo, foram apresentadas algumas das observações sobre a ciência na grade de programação da TV aberta em Belém. Cabe ressaltar que os resultados quantitativos oferecem subsídios para aprofundamentos qualitativos e indiciam estudos futuros. Em trabalhos em desenvolvimento serão analisados de forma mais detalhada o papel da publicidade na circulação midiática da ciência e na sua incorporação ao cotidiano e ao senso comum, dentre outros aspectos.

\section{Referências}

ANDRADE, Lacy V. B. Iguarias à hora do jantar: a presença de ciência e tecnologia nos telejornais diários. 2004. 266 f. Tese (Doutorado em Educação, Gestão e Difusão em Ciências) - Universidade Federal do Rio de Janeiro, Rio de Janeiro, 2004.

CARVALHO, Vanessa B. et al. Ciência na TV aberta brasileira: um perfil da programação diária da Rede Globo e Rede Record. In: XXXVIII Congresso Brasileiro de Ciências da Comunicação, 2015, Rio de Janeiro. Anais..., São Paulo: Intercom, 2015. Disponível em: $<$ http://portalintercom.org.br/anais/nacional2015/ resumos/R10-0822-1.pdf> . Acesso em: 17 abr. 2016.

GOMES. Neusa D. Publicidade: comunicação persuasiva. Porto Alegre: Sulina, 2008. 
MACHAD0, Arlindo. A televisão levada a sério. 3. ed. São Paulo: Editora Senac, 2003.

MALCHER, Maria A. Teledramaturgia: agente estratégico na construção da TV aberta brasileira. São Paulo: INTERCOM, 2009.

MASSARANI, Luisa. et al. Saúde aos domingos: uma análise da cobertura da pesquisa em medicina \& saúde no Fantástico. Revista Eletrônica de Comunicação, Informação \& Inovação em Saúde. 2013. Disponível em: < http://www.reciis.icict.fiocruz.br/index.php/ reciis/article/view/702/1347> . Acesso em: 27 jul. 2015. et al. Science journalism in Latin America: a case study of seven newspapers in the region. Journal of Science Communication, v. 4, n. 3, p. 1-8, Sep. 2005.

MÍDIA DADOS BRASIL. Televisão Aberta. Disponível em: < https://dados.media>. Acesso em: 05 dez. 2016.

MIRANDA, Fernanda C. Cartografia movente: uma postura de pesquisa em comunicação na Amazônia. 2013. 189 f. Dissertação (Mestrado em Comunicação) Universidade Federal do Pará, Belém, 2013.

PALLOTTINI, Renata. Dramaturgia de televisão. 2. ed. São Paulo: Perspectiva, 2012.

RAMALHO, Marina. A ciência no Jornal Nacional e na percepção do público. 2013. 341 f. Tese (Doutorado em Química Biológica) - Universidade Federal do Rio de Janeiro, Rio de Janeiro. et al. Ciência em telejornais: uma proposta de ferramenta para análise de conteúdo de notícias científicas. In: MASSARANI, Luisa; RAMALHO, Marina (Org.). Monitoramento e capacitação em jornalismo científico: a experiência de uma rede ibero-americana. Rio de Janeiro: Museu da Vida/Casa de Oswaldo Cruz/ Fiocruz; Ciespal, 2012.

RONDELLI, Daniella R. A ciência no picadeiro: uma análise das reportagens sobre ciência no programa Fantástico. 148 f. Dissertação (Mestrado) -
Universidade Metodista de São Paulo, São Bernardo do Campo, 2004.

SANTOS, Boaventura da S. Um discurso sobre as ciências. 11. ed. Porto: Edições Afrontamentos, 1999.

SOUZA, José Carlos A. de. Gêneros e formatos na televisão brasileira. São Paulo: Summus, 2004.

WALLERSTEIN, Immanuel et al. Para abrir as ciências sociais. São Paulo: Cortez, 1996.

WHITELEGG, Elizabeth et al. (In)visible witnesses: Investigating gendered representations of scientists, technologists, engineers and mathematicians on UK children's television. UK Resource Centre for Women in Science, Engineering and Technology, Bradford, 2008. 


\begin{tabular}{|c|c|}
\hline $\begin{array}{l}\text { Science on free-to-air TV: } \\
\text { an exploration of Belém-PA } \\
\text { broadcasters programming }\end{array}$ & $\begin{array}{l}\text { La ciencia en la TV abierta: } \\
\text { una exploración de la programación } \\
\text { de emisoras de Belém-PA }\end{array}$ \\
\hline $\begin{array}{l}\text { Abstract } \\
\text { This paper analyses the presence of science on the } \\
\text { program schedule of two free-to-air broadcaster } \\
\text { from Belém-PA, TV Liberal and Record Belém, } \\
\text { respectively retransmitting Rede Globo and Rede } \\
\text { Record. Based on the composite sample weeks and } \\
\text { content analysis, we mapped the presence of science } \\
\text { in the local programming, considering the local and } \\
\text { national productions. We highlight that science is } \\
\text { daily present in every time slot on free-to-air TV; that } \\
\text { advertising is one of the main agents maintaining } \\
\text { this scenario; and that the local program schedule is } \\
\text { focused on what is produced on a national scale, that } \\
\text { withers the local production and results in a lesser } \\
\text { presence of science. } \\
\text { Keywords } \\
\text { Free-to-air TV. Science. Local programming. }\end{array}$ & $\begin{array}{l}\text { Resumen } \\
\text { Este artículo analiza la presencia de la ciencia en } \\
\text { programación televisiva abierta en dos emisoras de } \\
\text { Belém-PA: la TV Liberal y la Record Belém, respectivas } \\
\text { retransmisoras de Rede Globo y Rede Record. A } \\
\text { partir de la técnica de semana construida y análisis } \\
\text { de contenido, cartografiamos la presencia de la } \\
\text { ciencia en la programación local, considerando las } \\
\text { producciones locales y nacionales. Destacamos que } \\
\text { la ciencia está presente diariamente en todas las } \\
\text { franjas horarias en la TV abierta; que la publicidad és } \\
\text { un de los principales agentes configuradores de este } \\
\text { escenario; y que la programación local és centrada en } \\
\text { la producción nacional, que resulta en una producción } \\
\text { local atenuada y con poca presencia de la ciencia. } \\
\text { Palabras clave } \\
\text { TV abierta. Ciencia. Programación local. }\end{array}$ \\
\hline
\end{tabular}




\section{Expediente}

A revista E-Compós é a publicação científica em formato eletrônico da Associação Nacional dos Programas de Pós-Graduação em Comunicação (Compós). Lançada em 2004, tem como principal finalidade difundir a produção acadêmica de pesquisadores da área de Comunicação, inseridos em instituições do Brasil e do exterior.

\section{E-COMPÓS I www.e-compos.org.br I E-ISSN 1808-2599}

Revista da Associação Nacional dos Programas de Pós-Graduação em Comunicação. Brasília, v.20, n.2, maio/ago. 2017. A identificação das edições, a partir de 2008, passa a ser volume anual com três números. Indexada por Latindex I www.latindex.unam.mx

\section{CONSELHO EDITORIAL}

Alda Cristina Silva da Costa, Universidade Federal do Pará, Brasil Alfredo Luiz Paes de Oliveira Suppia, Universidade Estadual de Campinas, Brasil Álvaro Larangeira, Universidade Tuiuti do Paraná, Brasil Ana Carolina D. Escosteguy, Pontifícia Universidade Católica do Rio Grande do Sul, Brasil Ana Regina Barros Rego Leal, Universidade Federal do Piauí, Brasil Ana Carolina Rocha Pessôa Temer, Universidade Federal de Goiás, Brasil Andrea França, Pontifícia Universidade Católica do Rio de Janeiro, Brasil André Luiz Martins Lemos, Universidade Federal da Bahia, Brasil Angela Cristina Salgueiro Marques, Faculdade Cásper Líbero, Brasil Ângela Freire Prysthon, Universidade Federal de Pernambuco, Brasil Antonio Carlos Hohlfeldt, Pontifícia Universidade Católica do Rio Grande do Sul, Brasil Arthur Ituassu, Pontifícia Universidade Católica do Rio de Janeiro, Brasil Bruno Campanella, Universidade Federal Fluminense, Brasil Cláudio Novaes Pinto Coelho, Faculdade Cásper Líbero, Brasil Carlos Eduardo Franciscato, Universidade Federal de Sergipe, Brasil Denise Tavares da Silva, Universidade Federal Fluminense, Brasil Eduardo Vicente, Universidade de São Paulo, Brasil Eliza Bachega Casadei, Escola Superior de Propaganda e Marketing - SP, Brasil Elizabeth Nicolau Saad Corrêa, Universidade de São Paulo, Brasil Erick Felinto de Oliveira, Universidade do Estado do Rio de Janeiro, Brasil Erly Vieira Júnior, Universidade Federal do Espírito Santo, Brasil Francisco de Assis, FIAM-FAAM Centro Universitário, Brasil Francisco Elinaldo Teixeira, Universidade Estadual de Campinas, Brasil Frederico de Mello Brandão Tavares, Universidade Federal de Ouro Preto, Brasil Gabriela Reinaldo, Universidade Federal do Ceará, Brasil

Gilson Vieira Monteiro, Universidade Federal do Amazonas, Brasil Gustavo Daudt Fischer, Universidade do Vale do Rio dos Sinos, Brasi Itania Maria Mota Gomes, Universidade Federal da Bahia, Brasil Jiani Adriana Bonin, Universidade do Vale do Rio dos Sinos, Brasil José Afonso da Silva Junior, Universidade Federal de Pernambuco, Brasil José Luiz Aidar Prado, Pontifícia Universidade Católica de São Paulo, Brasi
Juçara Gorski Brittes, Universidade Federal de Ouro Preto, Brasil Juliana Freire Gutmann, Universidade Federal da Bahia, Brasil Laura Loguercio Cánepa, Universidade Anhembi Morumbi, Brasil Letícia Cantarela Matheus, Universidade do Estado do Rio de Janeiro, Brasil Liziane Soares Guazina, Universidade de Brasília, Brasil Luíza Mônica Assis da Silva, Universidade Católica de Brasília, Brasil Maria Ataide Malcher, Universidade Federal do Pará, Brasil Maria Elisabete Antonioli, Escola Superior de Propaganda e Marketing - SP, Brasil Maria das Graças Pinto Coelho, Universidade Federal do Rio Grande do Norte, Brasil Marcel Vieira Barreto Silva, Universidade Federal da Paraiba, Brasil Marcia Tondato, Escola Superior de Propaganda e Marketing, Brasil Marli Santos, Universidade Metodista de São Paulo, Brasil Márcio Souza Gonçalves, Universidade do Estado do Rio de Janeiro, Brasil Mauricio Mario Monteiro, Universidade Anhembi Morumbi, Brasil Mauricio Ribeiro da Silva, Universidade Paulista, Brasil Mauro de Souza Ventura, Universidade Estadual Paulista, Brasil Mayka Castellano, Universidade Federal Fluminense, Brasi Micael Maiolino Herschmann, Universidade Federal do Rio de Janeiro, Brasil Mozahir Salomão Bruck, Pontifícia Universidade Católica de Minas Gerais, Brasil Nísia Martins Rosario, Universidade Federal do Rio Grande do Sul, Brasil Potiguara Mendes Silveira Jr, Universidade Federal de Juiz de Fora, Brasil Rafael Grohmann, FIAM-FAAM - Centro Universitário, Brasil Raquel Ritter Longhi, Universidade Federal de Santa Catarina, Brasil Regiane Regina Ribeiro, Universidade Federal do Paraná, Brasil Roberto Elísio dos Santos, Universidade Municipal de São Caetano do Sul, Brasil Rodolfo Rorato Londero, Universidade Estadual de Londrina, Brasil Sérgio Luiz Gadini, Universidade Estadual de Ponta Grossa, Brasil Simone Maria Andrade Pereira de Sá, Universidade Federal Fluminense, Brasil Simone Maria Rocha, Universidade Federal de Minas Gerais, Brasil Suzana Reck Miranda, Universidade Federal de São Carlos, Brasil Tarcyanie Cajueiro Santos, Universidade de Sorocaba, Brasil Tatiana Oliveira Siciliano, Pontifícia Universidade Católica do Rio de Janeiro, Brasil Veneza Mayora Ronsini, Universidade Federal de Santa Maria, Brasil

\section{CONSELHO CIENTÍFICO}

Cristiane Freitas Gutfreind, Pontifícia Universidade Católica do Rio Grande do Sul, Brasil | Eduardo Antônio de Jesus, Universidade Federal de Minhas Gerais, Brasil | Eduardo Morettin, Universidade de São Paulo, Brasil I Irene de Araújo Machado, Universidade de São Paulo, Brasil I Miriam de Souza Rossini, Universidade Federal do Rio Grande do Sul, Brasil

\section{COMISSÃO EDITORIAL}

Eduardo Antonio de Jesus, Universidade Federal de Minas Gerais, Brasil I Igor Pinto Sacramento, Universidade Federal do Rio de Janeiro, Brasil I Kelly Cristina de Souza Prudencio, Universidade Federal do Paraná, Brasil I Osmar Gonçalves dos Reis Filho, Universidade Federal do Ceará, Brasil

\section{CONSULTORES AD HOC}

Cesar Augusto Baio Santos, Universidade Federal do Ceará, Brasil I Lilian França Universidade Federal de Sergipe, Brasil I Maria Aparecida Baccega, Escola Superior de Propaganda e Marketing, Brasil I Márcia Benetti, Universidade Federal do Rio Grande do Sul, Brasil I Miguel Serpa Pereira, Pontifícia Universidade Católica do Rio de Janeiro, Brasil | Renato Essenfelder, Escola Superior de Propaganda e Marketing, Brasil

\section{EQUIPE TÉCNICA}

ASSISTENTE EDITORIAL Márcio Zanetti Negrini | REVISÃO DE TEXTOS Melina Santos | EDITORAÇÃO ELETRÔNICA Roka Estúdio I IMAGEM DE CAPA Silas de Paula

COMPÓS I www.compos.org.br

Associação Nacional dos Programas de Pós-Graduação em Comunicação

Presidente

Marco Roxo

Programa de Pós-Graduação em Comunicação - UFF marcos-roxo@uol.com.br

Vice-Presidente Isaltina Gomes Programa de Pós-Graduação em Comunicação - UFPE isaltina@gmail.com

Secretária-Geral

Gisela Castro

Programa de Pós-Graduação em Comunicação e Práticas de Consumo - ESPM castro.gisela@gmail.com

CONTATO I revistaecompos@gmail.com 